\section{REFERENCES}

BLACK, R. W. Incentive motivation and the parameters of reward in instrumental conditioning. Nebraska Symposium, in press.

BLOOM, J. M., \& MILSTEAD, J. Interactive effect of reward magnitude and intertrial interval on extinction behavior. Paper presented at Psychonomic Society Meeting, November 1969.

LOGAN, F. A. Incentive: How the conditions of reinforcement affect the performance of rats. New Haven: Yale University Press, 1960.

McCAIN, G. Magnitude effects after extended training. Paper presented at Psychonomic Society Meeting, November 1969.

SPENCE, K. W. Behavior theory and

\title{
Correlates of food competition behavior ${ }^{1}$
}

MARTIN MANOSEVITZ, CHARLES I. FITZSIMMONS, and THOMAS $R$. McCANNE, The University of Texas at Austin, Austin, Tex. 78712

Random-bred mice from a five-way cross of inbred strains were tested in the open field, running wheel, and food competition tests. various measures were intercorrelated to determine the associations between these behaviors. The results indicated that food competition behavior was positively associated with early running wheel activity, negatively correlated with open-field defecation, and negatively correlated with body weight measures There was no association between open-field activity and food competition. It was suggested that food competition behavior is partly determined by general activity and emotionality.

The ability of some members of a species to compete successfully against others for a limited food supply has survival value for the individual and could play an important role in natural selection and evolution. Diverse behaviors that may be important in natural selection, such as learning, emotionality, and activity, have often been studied by behavior geneticists, but social behaviors have been studied less often. The present experiment is concerned with studying, under laboratory conditions, the ability to compete for a limited food supply. The purpose of this experiment is to measure some possible correlates of food competition behavior, and to determine if this behavior is highly associated with other, particularly nonsocial, behaviors.

Food competition is a complex multidimensional behavioral pattern, and it is reasonable to assume that one or more simple behaviors or variables, like body conditioning. New Haven: Yale University Press, 1956.

WAGNER, A. R. Effects of amount and percentage of reinforcement and number of acquisition trials on conditioning and extinction. Journal of Experimental Psychology, 1961, 62, 234-242.

NOTE

1. These studies were supported in part by the Liberal Arts Organized Research Fund of the University of Texas at Arlington and in part by NIMH Grant No. 14686-01. Thanks are due to Kenneth Dyleski, who ran Experiment 1, and to Earl Isbell and Gary Gowins, who ran Experiment 2 . weight, may be associated with this behavior. To test this assumption, one may intercorrelate several measures with food competition scores and, in this way, determine the association between the various measures. If food competition performance is highly correlated with other, less complex behaviors, such as activity or emotionality, then behavior-genetic analyses of food competition must control for such factors.

In behavior genetic studies, intercorrelations between measures have seldom been reported. In many of these studies, inbred strains of mice were used and thus genetic variation was greatly reduced. When inbred strains are studied, intercorrelations within strains do not provide meaningful estimates of the interrelationships between variables because genetic and environmental variation is usually quite constricted. In fact, genetic variation should be close to zero, and if rigid laboratory conditions are maintained, environmental variation should be quite low. If intercorrelations between strains are computed, a large number of strains must be used because each strain is comparable to one individual. An alternate approach is to use mice that are genetically heterozygous. Such populations can be obtained by specific crosses, i.e., $F_{2} S$ and backcrosses or from a randomly bred line of mice. In this study, the latter approach was used.

$A$ random-bred line insures adequate genetic variation between animals to make correlation techniques appropriate. In this experiment, a laboratory-generated random-bred line of mice was used and each $S$ was measured on a number of behavioral traits; thus, it was possible to identify correlates of food competition behavior.

\section{METHOD}

A total of 60 (24 males, 36 females) 10th generation random-bred mice ${ }^{2}$ were used as Ss. The random line was constituted by crossing five inbred strains to form a foundation population. The five-way cross was generated by taking animals from the $\mathrm{RIII} / \mathrm{Crgl}$, C57BL/Crgl, $\mathrm{C} 3 \mathrm{H} / \mathrm{Crgl} / 2$, and $\mathrm{DBA} / \mathrm{Crgl} / 2$ inbred strains and crossing them, and then the fifth inbred strain, IsBi/Crgl, was added to the gene pool. Successive generations were produced by random mating.

Half the animals were exposed to an enriched environment from birth to 35 days of age. The details of this treatment and the test apparatus have been described by Manosevitz. ${ }^{3}$ Each $S$, starting at 38 days of age, was tested for 5 days in the open field, and urination, defecation, and activity were recorded. Between 70 and 107 days of age, each animal was tested in standard running wheels (Wahmann LC-34) for 4 consecutive days. Data from all but three Ss were available on the running wheel measure, because wheels malfunctioned for these animals. Activity readings were taken at the end of 30,60 , and $90 \mathrm{~min}$ and at the end of $24,48,72$, and $96 \mathrm{~h}$. Ss were started in the food competition test when they were between 95 and 156 days of age. The food competition test consisted of 5 days of

Table 1

Intercorrelation Matrix

\begin{tabular}{|c|c|c|c|c|c|c|c|c|c|}
\hline $\begin{array}{c}\text { Variable }^{\mathrm{a}} \\
1 \\
\end{array}$ & 2 & 3 & 4 & 5 & $6^{\mathrm{b}}$ & 7 & 8 & 9 & 10 \\
\hline $\begin{array}{l}1 \\
2 \\
3 \\
4 \\
5 \\
6 \\
7 \\
8 \\
9\end{array}$ & -.08 & $\begin{array}{c}.18 \\
-.32 *\end{array}$ & $\begin{array}{r}.17 \\
-.27 * \\
.41^{*}\end{array}$ & $\begin{array}{r}.05 \\
-.11 \\
.01 \\
.53^{*}\end{array}$ & $\begin{array}{c}-.07 \\
-.27^{*} \\
.11 \\
.28^{*} \\
.21\end{array}$ & $\begin{array}{c}-.15 \\
-.29^{*} \\
.16 \\
.34^{*} \\
.20 \\
.79^{*}\end{array}$ & $\begin{array}{c}.09 \\
-.27^{*} \\
.08 \\
.37^{*} \\
.28^{*} \\
.36^{*} \\
.50^{*}\end{array}$ & $\begin{array}{c}.01 \\
-.26^{*} \\
.03 \\
-.23^{*} \\
-.13 \\
-.20 \\
-.30^{*} \\
-.36^{*}\end{array}$ & $\begin{array}{c}.03 \\
-.33^{*} \\
.09 \\
-.17 \\
-.18 \\
-.16 \\
-.24^{*} \\
-.38^{*} \\
.90^{*}\end{array}$ \\
\hline
\end{tabular}

$a=60$ for all variables except 4 and $5 . N=57$ (running wheels malfunctioned for three $S$ s) See text for identification of variables.

$b$ Product-moment correlation for all variables except 6 which is point-biserial $* p<.05$ 
training in the apparatus and 5 days of competition trials. Each opposition pair was matched for sex and age and consisted of a control and an experimental (enriched treatment) $S$. Further procedural and testing details have been reported elsewhere (Manosevitz, in press).

The intercorrelation matrix consisted of 10 variables (see Table 1) as follows: (1) 5-day mean open-field urination, (2) 5-day mean open-field defecation, (3) 5-day mean open-field activity, (4) mean number of wheel revolutions during the first three $30-\mathrm{min}$ periods on Day 1, (5) 4-day mean number of revolutions, (6) 5-day win-lose score in food competition, scored by determining the winner of each daily competition match (the $S$ who spent more time eating at the food cup on each day was considered the winner on that day), and the $S$ who was the winner on three or more days was counted as the 5-day winner, (7) 5-day mean number of seconds eating during competition, (8) 5-day mean number of seconds eating during training, (9) ad lib body weight at start of food competition test, (10) 5-day mean body weight (deprivation) during food competition. The results of the intercorrelation analysis are presented in Table 1.

\section{RESULTS AND DISCUSSION}

Open-field urination was not significantly correlated with any of the other measures. This may be due to the low frequency and difficulty in reliably scoring this measure. These results, plus data from several other studies in our laboratory, suggest that urination is not a meaningful measure of emotionality. However, urination may be a useful measure of other behavior, such as territory marking.

Open-field defecation, generally assumed to be a measure of emotionality, was significantly and negatively correlated with every other variable, except the 4-day running wheel activity measure. As amount of defecation increases, open-field activity and early running wheel activity decrease, and eating time in the food competition apparatus during competition and training trials decreases. A negative relationship between open-field defecation and activity has been generally observed in rats (Denenberg \& Morton, 1962; Henderson, 1966; Whimbey \& Denenberg, 1967).
Thus, less emotional (low open-field defecation) mice are more active and perform better in the food competition task. It also appears that animals that defecate more in the open field are lighter animals. Thus defecation is not a positive function of body weight or presumably food intake. The absence of a significant negative correlation between open-field defecation and 4-day activity measure suggests that activity after an extended period of free access to the running wheel is not influenced by emotional factors, whereas early running wheel scores appear to be influenced by such factors.

Open-field activity was positively correlated with running wheel activity in the first $90 \mathrm{~min}$, but not with the 4-day running wheel measure. Open-field activity was not associated with any aspect of food competition or body weight. These results suggest that general activity during the first $90 \mathrm{~min}$ in the running wheel, may be partly determined by some of the same factors, i.e., emotionality, novelty, that influence open-field activity, but these factors are not as important in the longer running wheel activity measure. Open-field activity is often interpreted as an index of emotionality. Assuming such an interpretation, we see that this aspect of emotionality is not associated with food competition training scores or competition scores during opposition trials.

As expected, the 90-min running wheel scores were positively associated with the 4-day running wheel scores. However, these measures were only moderately correlated (.53), and thus one may conclude that early running wheel performance may be partly influenced by other factors such as emotionality or novelty. The 90-min activity measure was positively associated with all food competition measures and these correlations are all of the same general magnitude. Thus, food competition performance and training are associated with activity displayed during early exposure to the running wheels. However, the 4-day running wheel measure was associated only with food competition training scores. This is further evidence that the two running wheel measures are indices of different aspects of general activity.

The win-lose food competition measure is highly correlated with 5-day mean food competition scores, as one would expect, but only moderately correlated with food competition training performance. Thus, training in food competition only partly influences performance under test trials of active food competition. Further evidence for this conclusion is found in the moderate correlation between the 5-day mean number of seconds spent eating during competition and during training.

Food competition testing and training performance were negatively correlated with ad lib body weight and average deprivation weight. Eating in the food competition apparatus was not a positive function of body size as indicated by weight.

In summary, it appears that animals that are less emotional (i.e., defecate less in the open field) and more active in the first three 30 -min running wheel periods are more competitive and that larger animals are not more successful competitors. In addition, running wheel measure taken during the period of initial exposure to the wheels may be influenced by variables different from those influencing 4-day activity scores. Food competition performance is not a simple function of emotionality, activity, or body weight, but is a complex behavior pattern that appears to be partly determined by general activity and emotionality, as well as other behaviors.

\section{REFERENCES}

DENENBERG, V. H., \& MORTON, J. R. C Effects of environmental complexity and social groupings upon the modification of emotional behavior. Journal of Comparative \& Physiological Psychology, 1962, 55, 242-246. HENDERSON, N. D. Effects of intensity and spacing of prior stimulation on later emotional behavior. Journal of Comparative \& Physiological Psychology, 1966, 62, 441-448. MANOSEVITZ, M. Early environmental enrichment and mouse behavior. Journal of Comparative \& Physiological Psychology, in press. WHIMBEY, A. E., \& DENENBERG, V. H. Two independent behavior dimensions in open-field performance. Journal of Comparative \& Physiological Psychology, 1967, 63, 500-504. NOTES

1. This research was supported by USDP Grant 1598 from the National Science Foundation and Grant MH-16899 from the National Institute of Mental Health. We are grateful to Shirley K. Cloud and Hugh $\mathrm{H}$. Poyner for their assistance with the data analysis and Jan H. Bruell for reading and commenting on the manuscript.

2. We are grateful to Delbert D. Thiessen, who maintains this line at the University of Texas, for providing subjects for this experiment. 